\title{
Quantitative structural analysis of pulmonary vessels in isolated ventricular septal defect in infancy
}

\author{
Alison Hislop, Sheila G. Haworth, E. A. Shinebourne, and Lynne Reid \\ From the Departments of Experimental Pathology and Paediatric Cardiology, Cardiothoracic Institute, Bromp- \\ ton Hospital, London $\mathrm{SW}_{3}$
}

Structural changes in the pulmonary circulation were studied in the lungs of 5 infants dying with ventricular septal defect. Applying precise quantitative morphological techniques to the pulmonary vessels, it was possible to correlate pathological change with clinical and haemodynamic findings, and to identify two patterns of response.

Three of the infants (group I) presented in cardiac failure with a large pulmonary blood flow, dilated and tortuous pulmonary arteries, and fewer intra-acinar vessels than normal. Medial hypertrophy was moderate and affected chiefly the larger arteries, i.e. those with a diameter greater than $200 \mu \mathrm{m}$.

The other 2 infants (group 2) had a high pulmonary vascular resistance with an intermittent right-to-left shunt. The pulmonary arteries were of normal size and the reduction in the number of the arteries was less striking. Medial hypertrophy was greater than in the first group and affected all sizes of artery including those less than $200 \mu \mathrm{m}$ in diameter.

In both groups, muscle extended further along the axial pathway.

Muscular hypertrophy was found also in the vein wall in most cases and, as with the arteries, was more severe in those with a higher pulmonary vascular resistance.

These findings illustrate the variation in pulmonary vascular response in infants with a ventricular septal defect. It is suggested that in patients with a ventricular septal defect, arterial muscularity usually regresses after birth and a left-to-right shunt develops; secondary hypertrophy of the media then develops in response to the shunt. Our findings also suggest, however, that in some infants arterial muscle fails to regress postnatally so that pulmonary blood flow is never high and a right-to-left shunt develops soon after birth.

When an isolated ventricular septal defect is sufficiently large to permit equalization of the ventricular pressures, the direction and magnitude of intraventricular shunting is determined by the ratio of pulmonary to systemic vascular resistance.

In the fetus and at birth, pulmonary vascular resistance is high, and thus little physiological disturbance is produced, even by a large ventricular septal defect. In the normal infant pulmonary vascular resistance falls to a low, near adult, level by 2 weeks of age (Rudolph, 1970), but in the presence of a large ventricular septal defect postnatal fall in resistance is commonly delayed until the second or third month, at which time heart failure with a large left-to-right shunt supervenes (Lucas et al.,

Received 20 March 1975.
1961; Hoffman and Rudolph, 1965; Hoffman, 1971).

These clinical observations on the natural history of ventricular septal defect (Lucas et al., 196I; Hoffman, 197I) are supported by the pathological studies of Dammann and Ferencz (1956). They found a thinner media in the pulmonary arteries of young infants dying in cardiac failure than is normally present at birth, and suggested that postnatal regression of wall thickness permits a large left-toright shunt. A secondary increase in wall thickness was thought to develop only after the second month, while intimal change did not appear until the second year. Similarly, Wagenvoort and his colleagues (196I), using uninjected material, found an increase in medial area after 5 weeks of age and intimal proliferation by $\mathbf{I}$ year. 
In 195I, Civin and Edwards noted considerable medial hypertrophy, similar to that found in the fetus, in the pulmonary arteries of infants dying with large aortopulmonary communications. They suggested that this was caused by a persistence of the thick arterial wall of fetal life, implying only a small reduction in pulmonary vascular resistance after birth.

In an attempt to clarify the natural history of ventricular septal defect, clinical and haemodynamic features have been correlated with structural findings, based on detailed and precise quantitative examination of the pulmonary circulation (Elliott and Reid, 1965; Davies and Reid, 1970; Hislop and Reid, I972, I973a, b). Injection techniques permit, among other measurements, reliable assessment of diameter, thickness of muscle coat, and the degree of muscle extension to the periphery.

In the small series of 5 cases to which these quantitative methods of analysis have been applied, 2 types of structural response have been identified and correlated with the clinical features.

\section{Subjects and methods}

The clinical features of the 5 patients studied are presented in Table $\mathbf{r}$.

Group 1 consisted of 3 infants presenting in early infancy with signs of a large ventricular septal defect and a high pulmonary blood flow. In 2 infants (Cases I and 2) respiratory tract infections precipitated the development of cardiac failure at 6 weeks and 7 months, respectively, while the third (Case 3 ) presented at 3 months because of heart failure and failure to thrive. All infants were tachypnoeic and 2 had a bilateral chest bulge. All had a grade 4 to 6 pansystolic murmur, and I infant had an apical mitral flow murmur: the pulmonary component of the second sound was perhaps slightly accentuated in 2 cases (Cases $I$ and 2).

Group 2 comprised 2 infants (Cases 4 and 5) each of whom presented at 3 months of age with tachypnoea and intermittent cyanosis. No murmur was heard in Case 5 and only a short systolic murmur was present in Case 4, while in both the pulmonary component of the second

TABLE I Clinical features

\begin{tabular}{|c|c|c|c|c|}
\hline Case no. & $\begin{array}{l}\text { Age at } \\
\text { presentation } \\
\text { (mth) }\end{array}$ & $\begin{array}{l}\text { Age at } \\
\text { death } \\
\text { (mth) }\end{array}$ & $\begin{array}{l}\text { Gror } \\
\text { for } \\
\text { heigh }\end{array}$ & $\begin{array}{l}\text { rentile } \\
\text { weight }\end{array}$ \\
\hline Group I $\left\{\begin{array}{l}I \\
2 \\
3\end{array}\right.$ & $\begin{array}{l}\mathrm{I} \frac{1}{2} \\
7 \\
3\end{array}$ & $\begin{array}{r}3 \\
10 \\
6\end{array}$ & $\begin{array}{l}10 \\
25 \\
25\end{array}$ & $\begin{array}{l}<3 \\
<3 \\
<3\end{array}$ \\
\hline Group $2\left\{\begin{array}{l}4 \\
5\end{array}\right.$ & $\begin{array}{l}3 \\
3\end{array}$ & $\begin{array}{l}3.5 \\
5\end{array}$ & $\begin{array}{r}25 \\
3\end{array}$ & $\begin{array}{l}<3 \\
<3\end{array}$ \\
\hline
\end{tabular}

sound was loud, suggesting severe pulmonary hypertension.

\section{Chest $x$-rays}

The radiographs of all 5 patients were similar, showing cardiac enlargement and increased pulmonary vascular markings. Thus, appearances suggesting plethora were seen not only in patients found to have a high pulmonary flow (group I) but also in those with an intermittent right-to-left shunt (group 2).

\section{Electrocardiograms}

In both groups electrocardiograms showed signs of right ventricular hypertrophy, the $R$ wave in $V 4 R$ and $V I$ being higher than the mean for age. In cases in group 2 there were also signs of right atrial hypertrophy. No difference in the degree of right ventricular hypertrophy was demonstrable between the groups.

\section{Cardiac catheterization}

Four infants were catheterized under local anaesthesia and one under general anaesthesia. Oxygen saturation was measured using reflection oximetry, and intravascular pressures were measured by conventional techniques. Left ventriculograms (left anterior oblique position) and biplane angiocardiograms were performed.

The findings at cardiac catheterization are presented in Table 2. Pulmonary hypertension was present in all cases but two groups could be distinguished. In group I (Cases I, 2, and 3), pulmonary flow was high while resistance was normal or minimally raised. Case $I$ also had a left-to-right shunt through a small ductus arteriosus. In group 2, pulmonary flow was normal but pulmonary vascular resistance was high (8.5 and 11.8 arbitrary units $\left.{ }^{\star}\right)$; this was associated with a right-to-left shunt when the patients were breathing room air. After administration of 100 per cent oxygen for Io minutes, mean pulmonary arterial and aortic pressures remained similar but a small left-to-right shunt occurred.

\section{Clinical course}

Despite intensive medical treatment there was no clinical improvement and primary closure of the defect was performed in Cases 2, 3, and 5, the patients dying either during or immediately after surgery. Surgery was not attempted in Cases $I$ and 4.

\section{Preparation and examination of lung tissue}

Arterial injection was carried out in both lungs of Cases $I$ and 4 and in one lung each of Cases 2, 3, and 5; venous injection into the contralateral lung was performed in the three latter cases.

The pulmonary vessels, either arteries or veins, were injected with a Micropaque-gelatin suspension at $60^{\circ} \mathrm{C}$ and at a pressure of $100 \mathrm{~cm}$ water. This method gave distension of the pulmonary vessels down to a diameter of $15 \mu \mathrm{m}$ but no medium entered capillaries. The lungs were inflated with buffered formalin introduced at a $\star^{\star}$ Arbitary units : $\mathrm{mm} \mathrm{Hg} \div 1 / \mathrm{min}$ per $\mathrm{m}^{2}$ BSA. 
TABLE 2 Haemodynamic data

\begin{tabular}{|c|c|c|c|c|c|c|c|}
\hline & Case No. & $\begin{array}{l}\text { Pressures (mm } \\
\text { Pulmonary } \\
\text { artery }\end{array}$ & $\begin{array}{l}\text { Ag) } \\
\text { Aorta }\end{array}$ & $\dot{\grave{p}}_{\left(l / \min \text { per } m^{2}\right)}$ & $\dot{Q}_{p} / \dot{Q}_{s}$ & $\begin{array}{l}R_{\mathrm{PA}} \\
\text { (units) }\end{array}$ & $\begin{array}{l}\text { Oxygen } \\
\text { Saturation (\%) } \\
\text { Aorta }\end{array}$ \\
\hline \multirow{3}{*}{ Group I } & $\int$ & $\begin{array}{l}55 / 15 \\
m=29\end{array}$ & $65 / 35$ & $\star$ & $\star$ & $\star$ & $\star$ \\
\hline & 2 & $\begin{array}{l}46 / 23 \\
\mathrm{~m}=35\end{array}$ & $63 / 53$ & I5.6 & 5.5 & I.6 & 96 \\
\hline & 3 & $\begin{array}{l}65 / 47 \\
m=55\end{array}$ & $118 / 68$ & 8.7 & 2.5 & 4.6 & 98 \\
\hline \multirow[b]{2}{*}{ Group 2} & 4 & $\begin{array}{l}75 / 40 \\
\mathrm{~m}=50\end{array}$ & $65 / 40$ & 4.34 & - & 8.5 & 45 \\
\hline & 5 & $\begin{array}{l}92 / 50 \\
\mathrm{~m}=56\end{array}$ & $92 / 50$ & 4.4 & 1.3 & II.8 & 83 \\
\hline
\end{tabular}

* Unstable haemodynamic status during cardiac catheterization: calculations, therefore, unreliable.

Conversion from Traditional to SI units: $1 \mathrm{mmHg} \approx 0.133 \mathrm{kPa}$.

pressure of $45.5 \mathrm{~cm}$ of water through the trachea and allowed to flow until the pleural surfaces were tense.

Each fixed, injected lung was radiographed using a Watson $M X-2$ portable $x$-ray unit. Kodirex AutoProcess film was used at a tube distance of $50 \mathrm{~cm}$, using $50 \mathrm{kV}$ and $15 \mathrm{~mA}$ for 0.5 to $\mathrm{I} .5 \mathrm{~s}$, depending on the size of the lung. This film resolves vessels to a diameter of $160 \mu \mathrm{m}$ as separate lines. Films were developed by the 'X-mat' automatic process. The arteriogram or venogram showed the overall pattern of branching and was used to measure lumen diameter of the longest vessel in the lower lobe, at the hilum, and at 25 per cent intervals along its course.

The fixed specimen was then cut in a transverse plane into slices $0.5 \mathrm{~cm}$ thick, and blocks of tissue were selected for microscopical examination by a stratified random sampling technique. Vessel wall thickness was measured using a calibrated eyepiece graticule and related to external diameter (Davies and Reid, I970). In the normal lung of the fetus, child, or adult, percentage medial wall thickness ${ }^{1}$ is related to external diameter, being greatest in the smallest arteries and decreasing with increase in vessel size until it remains fairly constant in vessels of more than $300 \mu \mathrm{m}$ in diameter (Fig. 4). The structure of the vessel wall, either muscular, partially muscular, or non-muscular, was noted and the proportion of arteries within a given size range calculated. This indicated the extension of muscle to the periphery which was also assessed by relating artery structure to the nature of its accompanying airway, terminal or respiratory bronchiolus, or alveolar duct.

The number of arteries or veins and of alveoli per square centimetre of acinar tissue was calculated from the mean value of counts of 25 microscopical fields. Results from these cases were compared with results from normal lungs, treated in the same manner. 1 The media (including internal and external elastic laminæ)
is measured, and expressed as \% wall thickness:

$$
\% \text { wall thickness }=\frac{2 \times \text { medial wall thickness }}{\text { external diameter }} \times 100
$$

\section{Results}

\section{Pathological findings in the heart}

Three heart specimens were available for detailed examination. In Case 2 the ventricular septal defect resulted from malalignment of a hypoplastic conus septum with the anterior interventricular septum. This produced 20 per cent overriding of the aortic valve. Case 3 had a typical defect of the membranous septum, measuring $5 \mathrm{~mm}$ in diameter. In Case 5 the posterior portion of the membranous septum was deficient and, in addition, there was a posterior defect, $8 \mathrm{~mm}$ in diameter, in the apical part of the interventricular septum. Necropsy reports of Cases I and 4 described typical defects in the membranous septum, and Case I had, in addition, a secundum atrial septal defect and a small persistent ductus arteriosus.

In the 5 cases studied there was no correlation between the number or size of the defects and the severity of pulmonary vascular change.

Measurement of ventricular wall thickness showed biventricular hypertrophy: right ventricular hypertrophy was greatest in Case 5 which also had the highest pulmonary vascular resistance.

\section{Pathological findings in the lungs}

The lungs appeared normal macroscopically and the volume of the inflated lungs was normal for age. On histological examination, the pleura and connective tissue septa were thickened, and scattered areas of intra-alveolar oedema were present. The results of quantitative studies (Table 3) show differences in structural change in the two groups, though some overlap between the groups is apparent.

Arteriogram and venogram In group I lumen diameter of the proximal intrapulmonary arteries 
TABLE 3 Summary of pathological findings

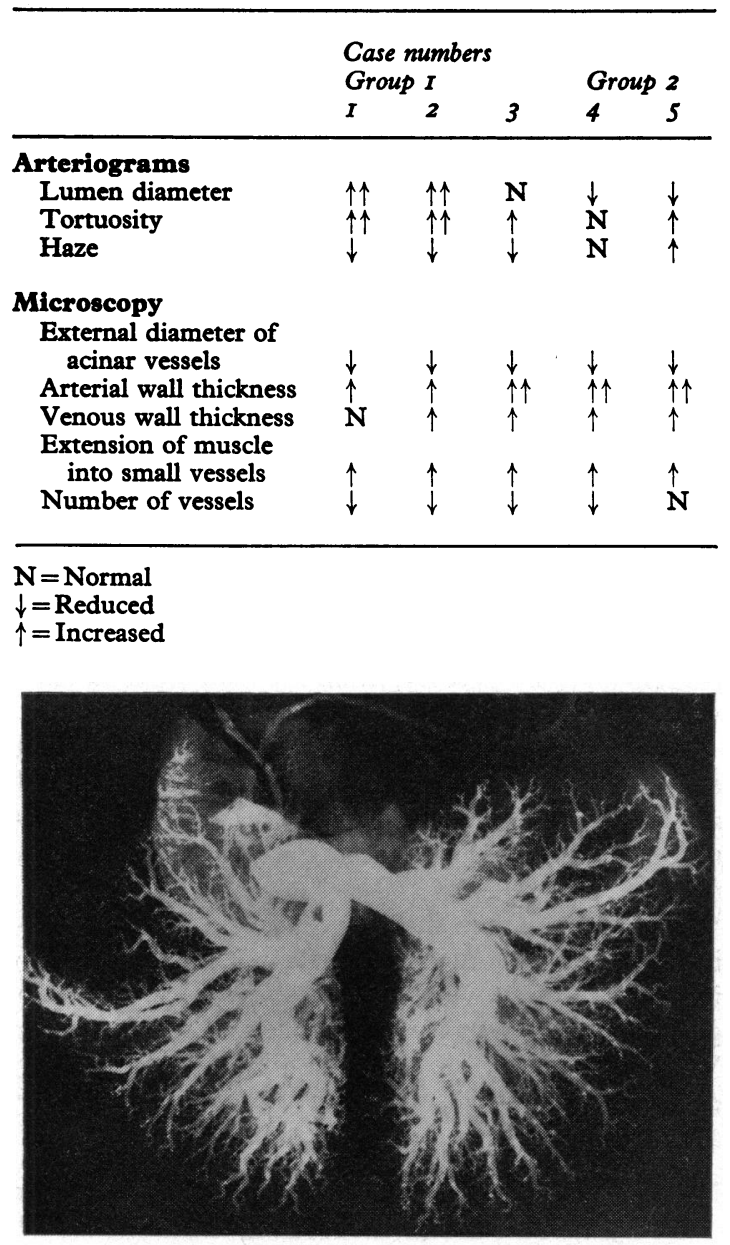

FIG. I Case I. Postmortem arteriogram after barium sulphate/gelatin injection. Arteries are wider than normal, tortuous, and the normal background haze of small vessels is missing. ( $\times 0.5$.)

and veins was increased, and the vessels were tortuous, either throughout their length or at the periphery (Fig. I). The density of background haze reflects the number of acinar vessels (Hislop and Reid, 1973c), and in these cases it was reduced as compared with normal. In contrast, in group 2 lumen diameter of the vessels was smaller than normal but a normal background haze was present (Fig. 2); in Case 5 the haze was even in excess of the normal. Tortuosity was not seen in Case 4 and was of only minimal degree in Case 5.

Size of peripheral arteries The peripheral arteries along the axial pathways can be 'landmarked'

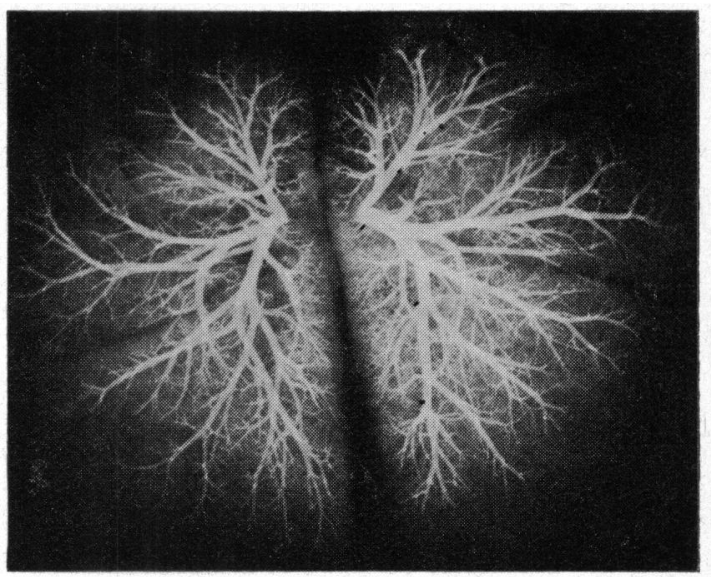

FIG. 2 Case 4. Postmortem arteriogram after barium sulphate/gelatin injection. Arteries are narrower than normal, no tortuosity is seen, and a background haze is present. $(\times 0.5$.
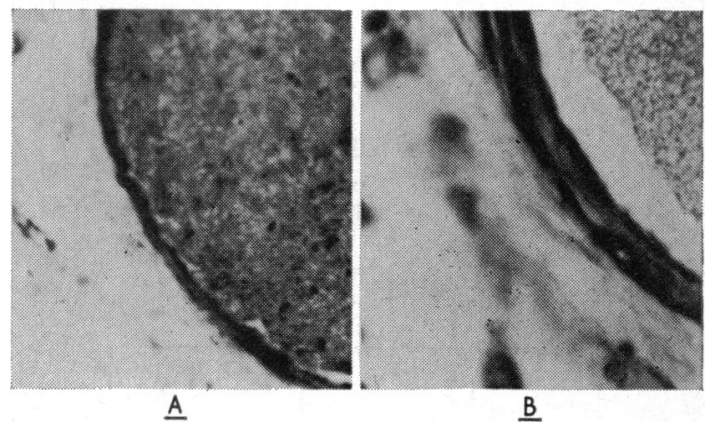

FIG. 3 Photomicrograph of wall of artery $100 \mu \mathrm{m}$ in external diameter from lung of $A$ ) normal 10-monthold child and $B$ ) Case 5 showing increased medial thickness. Measurement of wall thickness includes the internal and external elastic laminae. $(\times 750$.)

by identifying microscopically the accompanying airway, terminal or respiratory bronchiolus, or alveolar duct. Measurement of external diameter of these arteries showed, in all five cases, a reduction in size.

Structure of the vessel wall In all lungs percentage medial wall thickness at all size ranges was higher than normal for the age of child (Fig. 3). Comparing the results with the medial thickness at term, the severity of medial hypertrophy was found to vary with the size of the vessel (Fig. 4). In vessels larger than $300 \mu \mathrm{m}$ in diameter, wall thickness was at or above fetal level in all cases, but 


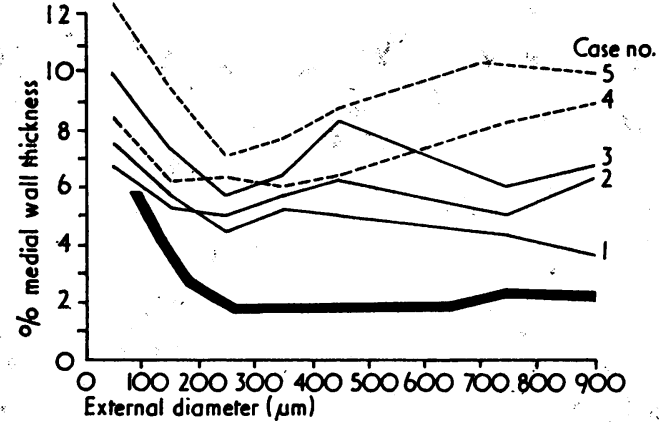

FIG. 4 Percentage medial wall thickness related to external diameter ( $\mu m)$, showing severe medial hypertrophy, peripheral extension of muscle, and progressive increase in muscularity with rising resistance; cases are numbered in order of increasing resistance.

group I;

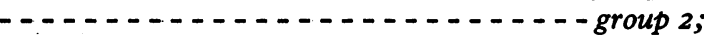

normal.

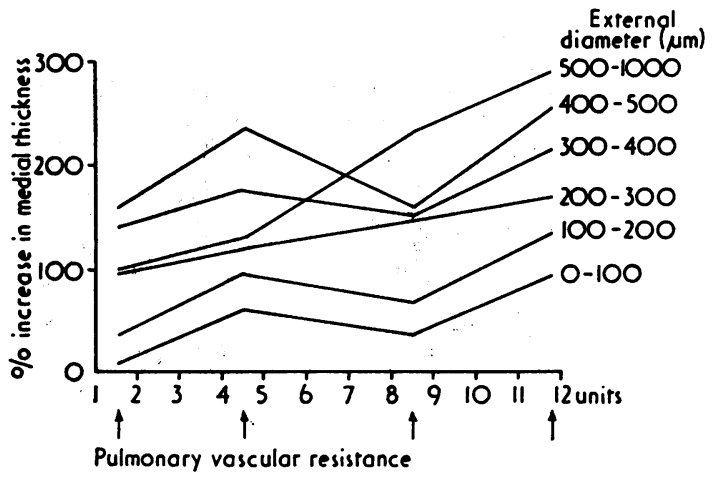

FIG. 5 Arterial wall thickening, expressed as a percentage increase of normal value, related to pulmonary vascular resistance. With increasing resistance, vessels of all sizes tend to show a progressive increase in wall thickness. (Cases 2-5.)

wall thickness in the smaller vessels was above fetal level in Cases 3, 4, and 5 only, the infants with the highest pulmonary vascular resistance.

In cases in group I the percentage medial wall thickness was lower than that in group 2 and, within each group, the higher the resistance the greater was the wall thickness. In Fig. 5 the percentage increase in wall thickness of vessels of different sizes is plotted against pulmonary vascular resistance as measured shortly before death. Increase in wall thickness affected large vessels in all cases, whereas severe medial hypertrophy in small vessels was

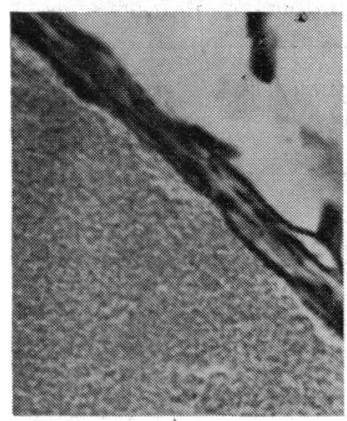

A

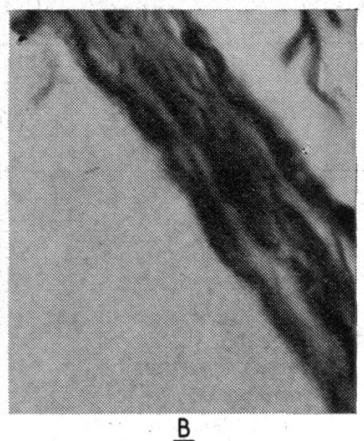

$\underline{B}$
FIG. 6 Photomicrograph wall of vein $625 \mu \mathrm{m}$ in external diameter from lung of $A$ ) normal 3-year-old child and $B$ ) Case 5 showing increased wall thickness caused by increase in muscle and number of elastic laminae. $(\times 750$.

present only in Cases 3, 4, and 5 with a pulmonary vascular resistance greater than 4.5 units.

Examination of vessels accompanying peripheral airways revealed a high proportion of muscularized arteries within the acinus - that is, muscle had extended further along the axial pathway than is normal.

In each specimen the degret of vein wall thickening paralleled the degree of arterial change and only in Case I was vein wall thickness normal. In group 2 the veins were arterialized, a term used by Wagenvoort (1970) to describe the presence of more elastic laminae in the muscle layer than is normal for age (Fig. 6).

Number of small pulmonary arteries In four out of 5 cases there was a reduction in number of arteries per unit area of lung periphery in comparison with the normal for similar age (Table 4). In 2 of these cases, the number of alveoli also was reduced. Serial reconstruction of an intralobular pathway in Case I showed a reduction in number of the supernumerary arteries, arteries that do not accompany airways and develop largely after birth. This suggests a failure of postnatal growth of arteries, and correlates with the lack of background haze on arteriograms.

Although little information is available about the number of veins per unit area in the normal lung, the figures in 3 cases of ventricular septal defect (Cases 2,3 , and 5) suggest a reduction in number of veins in this condition.

\section{Discussion}

In this series of patients with ventricular septal defect the children presented early in life either with signs of 
TABLE 4 Number of alveoli and vessels per unit area

\begin{tabular}{|c|c|c|c|c|c|c|c|}
\hline & Case No. & $\begin{array}{l}\text { Age } \\
\text { (mth) }\end{array}$ & $\begin{array}{l}\text { No. of } \\
\text { alveoli } / \mathrm{cm}^{2}\end{array}$ & $\begin{array}{l}\text { No. of } \\
\text { arteries } / \mathrm{cm}^{2}\end{array}$ & $\begin{array}{l}\text { No. of } \\
\text { veins } / \mathrm{cm}^{2}\end{array}$ & $\begin{array}{l}\text { Alveoli to } \\
\text { artery } \\
\text { ratio }\end{array}$ & $\begin{array}{l}\text { Alveoli to } \\
\text { vein } \\
\text { ratio }\end{array}$ \\
\hline Group I & $\left\{\begin{array}{l}1 \\
2 \\
3\end{array}\right.$ & $\begin{array}{r}3 \\
10 \\
6\end{array}$ & $\begin{array}{r}5157 \\
11130 \\
13633\end{array}$ & $\begin{array}{l}397 \\
424 \\
344\end{array}$ & $\begin{array}{l}-\overline{689} \\
861\end{array}$ & $\begin{array}{l}12.9 \\
26.3 \\
39.6\end{array}$ & $\begin{array}{l}-\overline{16.4} \\
15.8\end{array}$ \\
\hline Group 2 & $\left\{\begin{array}{l}4 \\
5\end{array}\right.$ & $\begin{array}{l}3 \\
5\end{array}$ & $\begin{array}{r}5731 \\
13275\end{array}$ & $\begin{array}{l}251 \\
662\end{array}$ & $\overline{702}$ & $\begin{array}{l}22.8 \\
20.1\end{array}$ & $\overline{18.9}$ \\
\hline $\begin{array}{l}\text { Normal } \\
\text { Subjects }\end{array}$ & & $\begin{array}{c}4 \\
\text { I0 } \\
3 y r\end{array}$ & $\begin{array}{l}11315 \\
10758 \\
10480\end{array}$ & $\begin{array}{l}529 \\
847 \\
874\end{array}$ & $\frac{-}{927}$ & $\begin{array}{l}22.2 \\
12.7 \\
12.0\end{array}$ & $\frac{\bar{Z}}{\mathrm{II.3}}$ \\
\hline
\end{tabular}

a large pulmonary blood flow or with an intermittent right-to-left shunt. Since ventricular septal defect does not commonly cause death at this age, the series is small but it was thought important to study these cases using precise methods of analysis; these have revealed different structural features of the pulmonary circulation in the two groups. By injection of the arterial or venous system at constant pressure, comparison between the vessels of lungs at various ages in health and disease is possible. The diameter of a vessel can be reliably assessed and, in the normal, the thickness of its muscle coat can be closely predicted from the external diameter. An artery can be identified by the airway it accompanies as well as by diameter, and it is thus possible to determine whether its size is appropriate to its position in the lung and whether muscle has extended into arteries that are smaller or more peripheral than is normal.

In the presence of a high pulmonary blood flow and low pulmonary vascular resistance, pulmonary arteries and veins are dilated and there is a moderate increase in their wall thickness. By contrast, a high pulmonary vascular resistance and low pulmonary blood flow are associated with pulmonary vessels of reduced calibre and with well-developed hypertrophy of the medial muscle coat of arteries and veins.

These features point to a variation in the natural history of ventricular septal defect during the first months of life. There was no evidence to suggest that infants in group 2 had ever had a large pulmonary flow as had those in group 1 . It seems that the course and pattern of change in the two groups differed from birth. Cases in group I behaved in the more usual way, presenting in cardiac failure at 3 months of age when regression of medial hypertrophy (Dammann and Ferencz, 1956) would normally have occurred. In contrast, in group 2 little regression appears to have taken place; the amount of muscle may have been normal at birth and failed to regress or there may have been excessive arterial muscle even in utero. These infants, though never in obvious cardiac failure, were abnormal from birth, with tachypnoea and poor weight gain.

\section{Relation between pulmonary vascular resis- tance and structural change in lung}

Muscle hypertrophy in a vessel is probably caused by an increase in transmural pressure (Hoffman, 1972) which is an early feature in ventricular septal defect, but is absent in most secundum atrial septal defects in which a large pulmonary blood flow is not initially associated with pulmonary hypertension. Increase in muscularity implies the possibility of greater vasoconstrictor tone, and extension of muscle along the arterial pathway, as in this series, increases the proportion of the pathway susceptible to vasoconstrictive agents. It is of interest that only in cases with the highest resistance did the smallest arteries show a considerable increase in wall thickness (Fig. 5). Tonic vasoconstriction of these small vessels may be important in increasing pulmonary vascular resistance. In the newborn infant, it is these small arteries that dilate (Wagenvoort and Wagenvoort, 1966) and they may well be of major importance in lowering pulmonary vascular resistance at birth. In the presence of a high pulmonary blood flow only the larger vessels, those greater than $300 \mu \mathrm{m}$ in diameter, showed severe medial hypertrophy, perhaps as a result of incomplete postnatal regression of muscle.

The role of vasoconstriction in initiating and/or maintaining pulmonary hypertension is not clear. Individual susceptibility to stimuli causing vasoconstriction varies widely, and Brammel and associates (197I) suggested that children who develop the 'Eisenmenger syndrome' are unusually susceptible to such stimuli.

In the present context, increase in muscularity might indicate increased susceptibility to vasoconstriction dating either from, or soon after, birth. 
Alternatively, increased muscularity may not have been concerned in the initial vasoconstrictor response, but once this had occurred increase in transmural pressure might lead to muscle hypertrophy.

Vasoconstriction and medial hypertrophy narrow the vessel lumen and the velocity of blood flow increases. Fry (1968) showed that in the experimental animal increasing the velocity of blood flow leads to increased shearing stresses which damage the intima.

Intimal change in ventricular septal defect is rare however during the first year of life, and did not occur in the present series. Another infant with ventricular septal defect admitted to our unit died at 9 months of age with severe intimal proliferation and fibrosis though the pulmonary artery had been adequately banded at 3 months of age and the defect closed at 6 months of age. This case raises the possibility that intimal change can, though rarely, follow severe medial hypertrophy despite early reduction of pulmonary flow and pressure.

In addition to medial hypertrophy and intimal change encroaching on the vessel lumen, narrowing can also result from external compression. All these patients with ventricular septal defect had perivascular oedema which may have contributed to an increased pulmonary vascular resistance (West, Dollery, and Heard, 1965) as seen in mitral stenosis where a raised left atrial pressure can also cause reflex pulmonary arterial vasoconstriction.

In the normal subject, about one-third of the pulmonary vascular resistance can be attributed to the pulmonary venous bed (Brody, Stemmler, and Dubois, 1968). Thus, medial hypertrophy and 'arterialization' of the walls of pulmonary veins, seen in ventricular septal defect, will increase vasoconstrictor tone and must tend to increase pulmonary vascular resistance. Changes in the veins could be a response to the arterial changes or could be caused by pulmonary venous hypertension resulting from high left atrial pressure. The former seems more likely, since 'arterialization' of veins is only seen when arterial changes are severe.

Reduction in arterial number in these cases of ventricular septal defect occurred both with and without a high pulmonary vascular resistance, and this finding differs from that seen in older children with cystic fibrosis, in whom it has been found that the higher the resistance (as assessed by the degree of right ventricular hypertrophy) the fewer the intra-acinar arteries (Reid and Ryland, 1973). The reason for this reduction is not clear, but it is likely that a reduction in vessel number represents a failure of postnatal multiplication of arteries.

Since it has already been reported that a low pulmonary blood flow, as in tetralogy of Fallot
(Hislop and Reid, 1973c), is associated with an increased number of small intra-acinar arteries, it is tempting to argue that, in patients in group I, reduced arterial multiplication was a result of the increased pulmonary flow. It cannot be ruled out, however, that failure to multiply represents an inherent abnormality of the pulmonary circulation.

In a variety of other forms of pulmonary hypertension - either primary or idiopathic in type (Anderson, Simon, and Reid, I973) or when experimentally produced in rats by hypoxia (A. Hislop, personal observation) or Crotalaria spectabilis feeding (Hislop and Reid, 1974) - a reduction in the number of small vessels has been demonstrated. This represents a disappearance of vessels rather than a failure of arteries to grow. The part played by a reduction in arterial number in the pathogenesis and persistence of a high pulmonary vascular resistance is not clear, since, exexperimentally, a conspicuous loss in vessel number persists even when right ventricular hypertrophy and arterial medial hypertrophy have regressed during a recovery period (Hislop and Reid, I974).

The sequel to a reduction in the pulmonary vascular bed is important. With normal growth, cardiac output increases, yet pulmonary artery pressure stays the same. The number of acinar vessels increases many times in order to accommodate the increased flow. If this multiplication fails to occur, pulmonary artery pressure may rise and secondary changes in the pulmonary vessels then develop.

\section{Problems associated with clinical diagnosis of pulmonary vascular disease}

The present findings have shown that measurement of a high pulmonary vascular resistance in infancy does not necessarily imply irreversible intimal change (Heath and Edwards, 1958), but it is important to note that even with a low pulmonary vascular resistance considerable medial hypertrophy was already present at 6 weeks of age.

In any patient with a large ventricular septal defect if a high pulmonary vascular resistance does not fall in response either to inhalation of 100 per cent oxygen or to the administration of other vasodilator agents, the case is usually considered inoperable. The rarity of intimal change in infancy suggests that at this age most patients should show a satisfactory response, but in practice, as in this series, this does not always happen. The absence of intimal change in such patients with an apparently 'fixed' high pulmonary vascular resistance may help to explain why failure to respond to vasodilator agents does not always mean a poor prognosis (Wagenvoort and Wagenvoort, 1974). It is 
not yet known, however, whether there is a level of medial hypertrophy beyond which a successful surgical outcome is unlikely.

We thank Dr. G. A. H. Miller who performed several of the catheterizations, and Dr. M. C. Joseph for permission to report on four of his cases.

\section{References}

Anderson, E. G., Simon, G., and Reid, L. (1973). Primary and thrombo-embolic pulmonary hypertension: a quantitative pathological study. Fournal of Pathology, $110,273$.

Brammel, H. L., Vogel, J. H. K., Pryor, R., and Blount, S. G. (197I). The Eisenmenger syndrome. A clinical and physiologic reappraisal. American fournal of Cardiology, 28, 679.

Brody, J. S., Stemmler, E. J., and Dubois, A. B. (1968). Longitudinal distribution of vascular resistance in the pulmonary arteries, capillaries and veins. Fournal of Clinical Investigation, 47, 783.

Civin, W. H., and Edwards, J. E. (195I). The postnatal structural changes in the intrapulmonary arteries and arterioles. Archives of Pathology, 51, 192.

Dammann, J. F., Jr., and Ferencz, C. (1956). The significance of the pulmonary vascular bed in congenital heart disease. III. Defects between the ventricles or great vessels in which both increased pressure and blood flow may act upon the lungs and in which there is a common ejectile force. American Heart fournal, 52, 210.

Davies, G., and Reid, L. (1970). Growth of the alveoli and pulmonary arteries in childhood. Thorax, 25, 669.

Elliott, F. M., and Reid, L. (1965). Some new facts about the pulmonary artery and its branching pattern. Clinical Radiology, 16, 193.

Fry, D. L. (1968). Acute vascular endothelial changes associated with increased blood velocity gradients. Circulation Research, 22, 165.

Heath, D., and Edwards, J. E. (1958). The pathology of hypertensive pulmonary vascular disease. A description of six grades of structural changes in the pulmonary arteries with special reference to congenital cardiac septal defects. Circulation, 18, 533.

Hislop, A., and Reid, L. (1972). Intrapulmonary arterial development during fetal life: branching pattern and structure. Fournal of Anatomy, 113, 35.

Hislop, A., and Reid, L. (1973a). Pulmonary arterial development during childhood: branching pattern and structure. Thorax, 28, 129.

Hislop, A., and Reid, L. (1973b). Fetal and childhood de- velopment of the intrapulmonary veins in man: branching pattern and structure. Thorax, 28, 313.

Hislop, A., and Reid, L. (I973c). Structural changes in the pulmonary arteries and veins in tetralogy of Fallot. British Heart fournal, 35, 1178.

Hislop, A., and Reid, L. (1974). Arterial changes in Crotalaria spectabilis-induced pulmonary hypertension in rats. British Fournal of Experimental Pathology, 55, 153.

Hoffman, J. I. E. (I97I). Ventricular septal defect. Indications for therapy in infants. Pediatric Clinics of North America, 18, 1091.

Hoffman, J. I. E. (1972). Diagnosis and treatment of pulmonary vascular disease. Birth Defects, 8, 9.

Hoffman, J. I. E., and Rudolph, A. M. (1965). The natural history of ventricular septal defects in infancy. American Fournal of Cardiology, 16, 634 .

Lucas, R. V., Jr., Adams, P., Jr., Anderson, R. C., Meyne, N. G., Lillehei, C. W., and Varco, R. L. (I96I). The natural history of isolated ventricular septal defect. A serial physiologic study. Circulation, 24, 1372.

Reid, L., and Ryland, D. (1973). The pulmonary circulation in cystic fibrosis. In Fundamental Problems of Cystic Fibrosis and Related Diseases, p. 195. Ed. by John A. Mangos and Richard C. Talamo. Symposia Specialists Medical Books, Miami, Florida and Intercontinental Medical Book Corporation, New York.

Rudolph, A. M. (1970). The changes in the circulation after birth. Their importance in congenital heart disease. Circulation, 41, 343.

Wagenvoort, C. A. (I970). Morphologic changes in the intrapulmonary veins. Human Pathology, 1, 205.

Wagenvoort, C. A., Neufeld, H. M., Dushane, J. W., and Edwards, J. E. (196r). The pulmonary arterial tree in ventricular septal defect. A quantitative study of anatomic features in fetuses, infants, and children. Circulation, 23, 740.

Wagenvoort, C. A., and Wagenvoort, N. (1966). The pulmonary vascular bed in the normal fetus and newborn. In The Heart and Circulation in the Newborn and Infant (An International Symposium), p. 201. Ed. by D. E. Cassels. Grune and Stratton, New York.

Wagenvoort, C. A., and Wagenvoort, N. (1974). Pathology of the Eisenmenger syndrome and primary pulmonary hypertension. Advances in Cardiology, 11, 123.

West, J. B., Dollery, C. T., and Heard, B. E. (1965). Increased pulmonary vascular resistance in the dependent zone of the isolated dog lung caused by perivascular edema. Circulation Research, 17, 191.

Requests for reprints to Professor Lynne Reid, Department of Experimental Pathology, Cardiothoracic Institute, Brompton Hospital, London SW3 $6 \mathrm{HP}$. 